Acta Haemat. 1972;48:321

\title{
25 Years of Acta Haematologica
}

Twentyfive years ago, this journal was founded with the understanding and great help of Dr. Heinz Karger, publisher at that time. The first issues contained mostly articles on clinical and morphological questions.

The rapid development and enlargement of the field of hematology, including discoveries in morphologic details in blood and bone marrow cells, in physiology and pathophysiology of the regulations of blood cells and their kinetics, chemotherapy, genetics, new facts on animal leukemia, already started to be reflected in articles several years after our journal was launched, now, such topics predominate.

An ever-increasing number of significant original articles from all parts of the world is now received; we are grateful to our Editorial Board and our reviewers for their help in evaluating the manuscripts. We have reason to expect that Acta Haematologica will retain its role as an international journal of clinical and experimental hematology.

The Editors-in-Chief and the Publisher 